\title{
Retención de plaguicidas en zonas amortiguadoras. Caso del isoproturon
}

\author{
I. Madrigal-Monárrez ${ }^{1}$, P. Benoit ${ }^{1}$, E. Barriuso ${ }^{1}$, B. Réal ${ }^{2}$, A. Dutertre ${ }^{2}$ y M. Moquet ${ }^{2}$ \\ ${ }^{1}$ INRA, Unité Environnement et Grandes Cultures, 78850 Thiverval-Grignon. Francia \\ ${ }^{2}$ ARVALIS, Service Techniques de Production, 80200 Estrées-Mons. Francia \\ E-mail: i.madrigal@unesco.org
}

(Recibido: noviembre de 2005 ; aceptado: septiembre de 2006)

\section{Resumen}

La instalación de zonas amortiguadoras es una de las soluciones propuestas para combatir la contaminación de aguas superficiales por plaguicidas. Los trabajos existentes muestran que estas zonas pueden limitar el transporte de agroquímicos hacia los cuerpos de agua. Sin embargo, existe muy poca información sobre el devenir de los productos interceptados, devenir que está relacionado con el funcionamiento fisicoquímico y biológico de estas zonas. En este trabajo se evaluó la retención de un herbicida, el isoproturon, en suelos provenientes de barreras de hierba, zonas arboladas y parcelas de cultivo del sitio experimental de ARVALIS en la Jaillière, Francia. Los experimentos fueron realizados en condiciones controladas de laboratorio utilizando el isoproturon marcado con ${ }^{14} \mathrm{C}$ en el anillo bencénico. Los resultados muestran que la retención del isoproturon es más fuerte en los suelos de las zonas amortiguadoras que en los de la parcela de cultivo, particularmente en los horizontes superficiales donde el contenido de materia orgánica es más elevado. Asimismo, la desorción de la molécula es más difícil en los horizontes superficiales de las zonas amortiguadoras que en el horizonte de trabajo de la parcela de cultivo. Estos resultados confirman el interés potencial de los dispositivos amortiguadores en la protección de los cuerpos de agua superficiales contra la contaminación de origen agrícola.

Descriptores: Plaguicidas, contaminación, retención, materia orgánica, zonas amortiguadoras.

\begin{abstract}
The in stalla tion ofbuffer zones is one of the solu tions pro posed to com bat surface wa tercontam ina tion by pes ticides. Ex isting stud ies show that these zones can limit the trans fer of agrochemicals to wa terbod ies. However, very lit tle in for ma tionex ists about what hap pens to the in ter cepted prod ucts. Their evo lu tion is re lated to the physiochemical and bio log ical func tion ing of these buffer zones. This study ex am ined the re ten tion of a her bicide, isoproturon, in soils from grassed buffer strips, for est area and crop ped soil from the ARVALIS ex per imen tal site in La Jaillière, France. Theex per iments werecar ried out un der con trolled lab o ra tory con di tions us ing isoproturon marked with ${ }^{14} \mathrm{C}$ in the ben zene ring. The re sults show that the re ten tion of the isoproturon was greater in the soils from the buffer zones than in the soils from the crop ped soil, par tic u larly in sur face ho ri zons, which have a higher con tent in or ganic mat ter. In ad di tion, the desorption of the mol e cule is more difficult in the sur face ho rizons of the buffer zones than in the worked layer of the crop ped soil. These find ings con firm the po ten tial value of buffer zones in pro tect ing sur face wa ter from agriculturalcontaminants.
\end{abstract}


Keywords: Pesticide, contamination, sorption, soilorganic matter, buffer zones, water.

\section{Introducción}

Desde hace varios años, los agroquímicos utilizados en la agricultura son asociados a la degradación del medio ambiente, debido a la contaminación de los cuerpos de agua por plaguicidas (Schiavon et al., 1995; Louchart et al., 1998; Bounet et al., 2002). La instalación de zonas amortiguadoras es una de las soluciones propuestas para combatir este tipo de contaminación (Patty, 1997; CORPEN, 1997). Existen diferentes tipos de zonas amortiguadoras como las barreras de hierba (grassed buffer strips) y las zonas arboladas. Las barreras de hierba son hasta la actualidad, los dispositivos más estudiados. Los trabajos existentes muestran que más del $70 \%$ de los plaguicidas solubles e insolubles transportados en las escorrentías, pueden ser retenidos por estos dispositivos (Patty, 1997; Patty et al., 1997). La eficiencia de las barreras de hierba obliga a cuestionarse sobre los riesgos de contaminación del manto freático por las escorrentías que pueden infiltrase a través de estas zonas y sobre el futuro de los productos interceptados. Respecto al primer punto, los resultados obtenidos por Soullier et al., (2002) a partir de una simulación de escorrentías en una barrera de hierbas del sitio experimental de La Jaillière, Francia, confirman los obtenidos previamente en el mismo sitio por Patty (1997), que muestran que la infiltración es uno de los principales factores que contribuyen a la disipación de plaguicidas en el seno de estos dispositivos. Sin embargo, no existe mucha información sobre el papel de los otros mecanismos implicados (Figura 1) como la retención de plaguicidas en los horizontes de suelo atravesados por las escorrentías. Asimismo, no se ha cuantificado aún la participación relativa de cada mecanismo. El objetivo de este trabajo fue caracterizar las capacidades de depuración de un herbicida, el isoproturon (IPU), en los suelos de diferentes barreras de hierba y de una zona arbolada en lo que respecta principalmente a su retención (movilidad). El comportamiento del IPU en las zonas amortiguadoras fue comparado con el observado en los suelos de una parcela de cultivo utilizados como suelo testigo.

\section{Materiales y métodos}

\section{Características de los suelos y el plaguicida estudiado}

Los suelos utilizados en el estudio, provienen del sitio experimental de ARVALIS de La Jaillière, situado en la Loira Atlántica al Oeste
Parte inferior

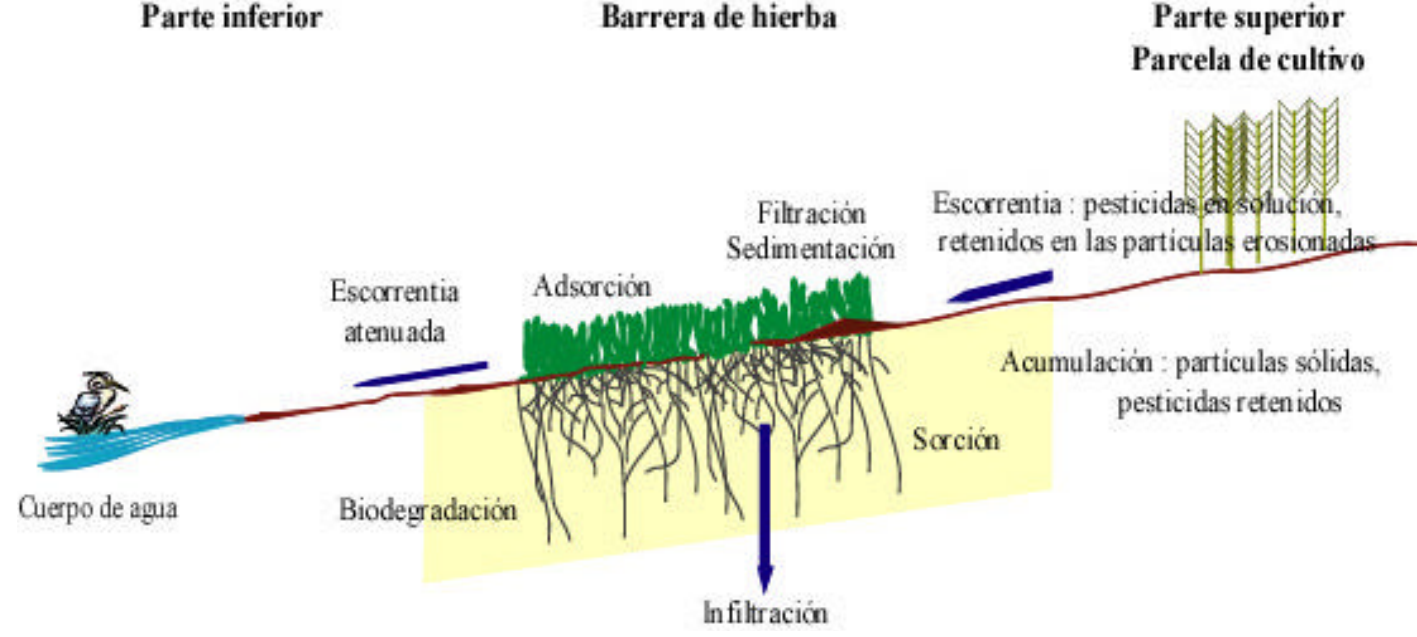

Figura 1. Mecanismos de acción de un dispositivo con hierbas: caso de los agroquímicos, (Patty, 1997). 
de Francia (Figura 2). El sitio experimental se ubica en una zona de formaciones volcánicas sedimentarias y el suelo del sitio es poco profundo e hidromorfo (Patty et al., 1997; Patty, 1997). Las condiciones climáticas del sitio están bajo la influencia oceánica y la pluvometría promedio anual es de $650 \mathrm{~mm}$, distribuida principalmente en el invierno y la primavera. Las temperaturas en el año son relativamente bajas: $4^{\circ} \mathrm{C}$ en el invierno y $18^{\circ} \mathrm{C}$ en el verano (temperaturas promedio diarias).

Los dispositivos experimentales estudiados (Figura 2) fueron cuatro barreras de hierba (BE), una zona arbolada (ZB) y una parcela de cultivo (PC). Las BE constituidas de pasto inglés tienen diferentes longitudes $(0,6,12$ y $18 \mathrm{~m})$ y fueron instaladas en la parte inferior de una parcela de cultivo en 1992 (Patty et al., 1997; Real et al., 1997). La PC es utilizada con una rotación de cultivo maíz-trigo. La ZB considerada está compuesta de castaños, tiene una edad aproximada de 80 años y forma parte del mismo sitio experimental. La toma de muestras se realizó en el invierno de 1999 a diferentes profundidades para diferenciar los horizontes afectados por el trabajo del suelo o por la instalación de una cubierta vegetal permanente. Las muestras de suelo fueron tomadas con una pequeña pala para la cama superficial de hojas y las capas superficiales. Para los horizontes subyacentes de suelo, el levantamiento fue hecho con un taladro. Se recolectaron dos horizontes superficiales orgánicos 0-2 y 2-10 cm de la ZB (Figura $3)$. Se distinguieron cuatro niveles de profundidad: 0-2, 2-13, 13-30, 30-60 cm de las BE, sobre la base de criterios morfológicos: color relacionado con el contenido de materia orgánica (MO), densidad y profundidad de las raíces. Finalmente, de la PC se recolectaron dos horizontes correspondientes al horizonte de trabajo $(0-30 \mathrm{~cm})$ y al horizonte subyacente $(30-60 \mathrm{~cm})$.

Las muestras fueron conservadas en una hielera hasta el regreso al laboratorio en donde se mezclaron para obtener una masa representativa, asimismo, una parte de aproximadamente $3 \mathrm{Kg}$ fue secada sobre hojas de papel filtro de 2 a 3 días en condiciones ambientales de laboratorio. La muestra de suelo se conservó en una cámara fría a $4^{\circ} \mathrm{C}$ hasta su utilización. Las características analíticas de los suelos (Tabla 1) fueron obtenidas por el laboratorio de análisis de suelo del INRA de Arras, Francia, a partir de muestras cernidas a $2 \mathrm{~mm}$, utilizando el método basado en la norma francesa X 31-107 (AFNOR, 1999). Los contenidos de carbono y nitrógeno de los suelos fueron determinados con un Analizador de Carbono Orgánico Total (TOC-5000A, Shimadzu) acoplado a un Módulo para Muestras Sólidas (SSM-5000A, Shimadzu) y un Analizador NA 1500 CN (Fisons Instrument), respectivamente. Todos los análisis fueron realizados por triplicado.
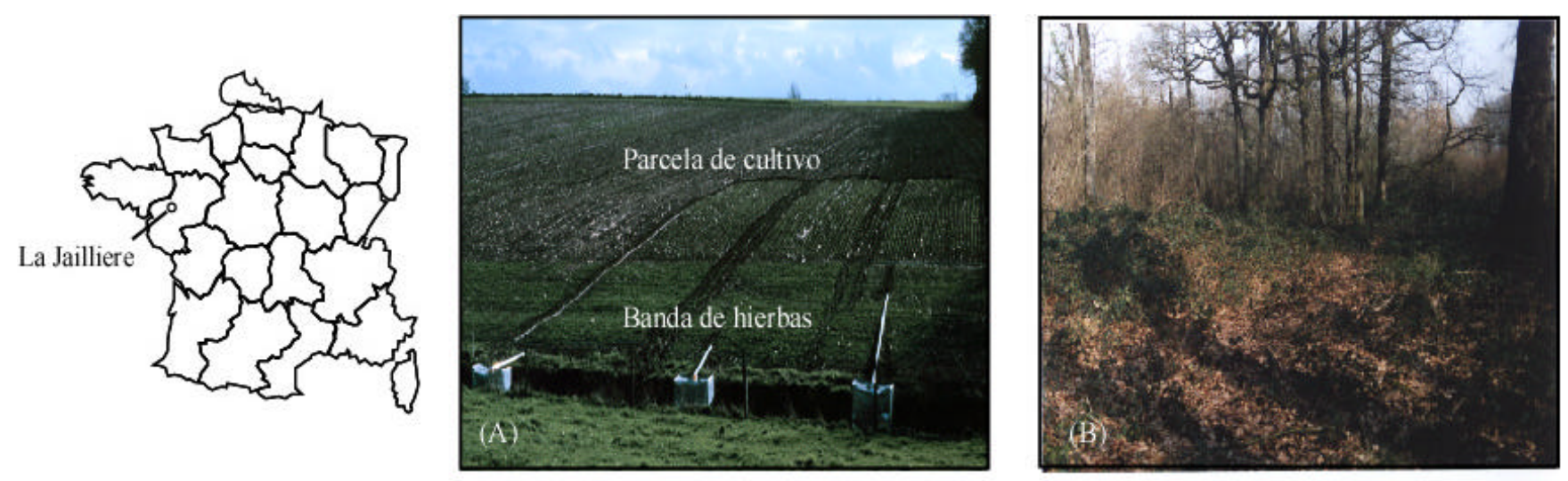

Figura 2. Dispositivos experimentales instalados en el sitio de ARVALIS de La Jaillière. (A) Barreras de hierba en la parte infe rior de una parcela de cultivo. (B) Zona arbolada. 

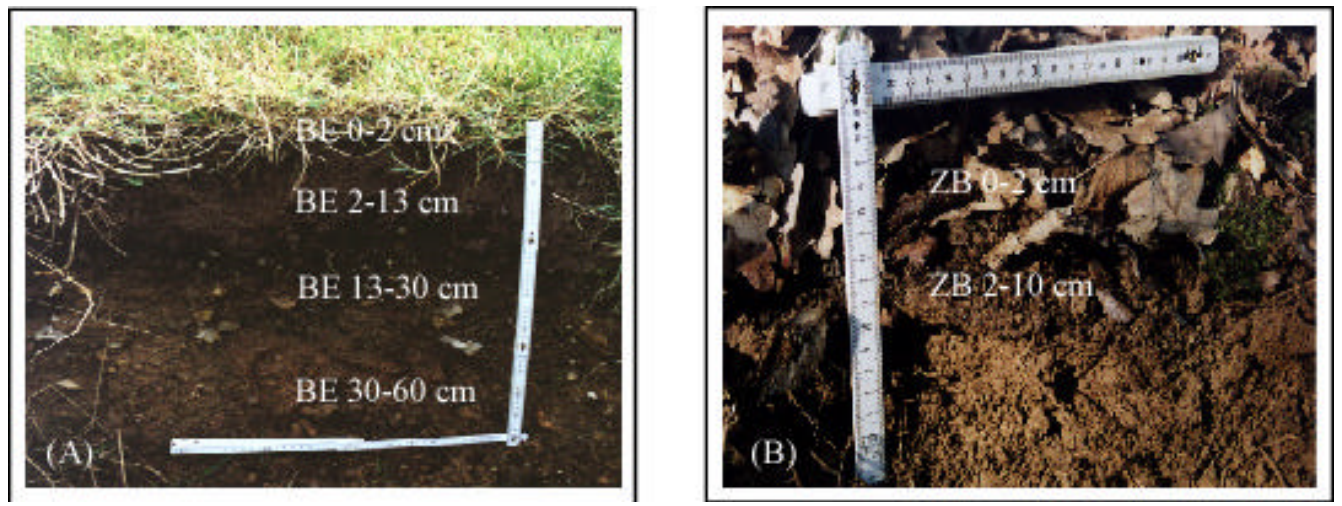

Figura 3. Perfiles de los suelos levantados. (A) Barrera de hierba y (B) Zona Arbolada

Tabla 1. Características de los suelos utilizados en el estudio

\begin{tabular}{|c|c|c|c|c|c|c|c|c|c|}
\hline $\begin{array}{l}\text { Dispositivo } \\
\text { Profundidad } \\
(\mathrm{cm})\end{array}$ & $\begin{array}{c}\mathrm{pH} \\
\text { agua }\end{array}$ & C & $\mathrm{N}$ & C:N & $\begin{array}{l}\text { Arenas } \\
\text { gruesas }\end{array}$ & $\begin{array}{l}\text { Arenas } \\
\text { finas }\end{array}$ & $\begin{array}{l}\text { Limos } \\
\text { gruesos }\end{array}$ & $\begin{array}{l}\text { Limos } \\
\text { finos }\end{array}$ & Arcillas \\
\hline & & $\longrightarrow$ & $\mathrm{kg}^{-1}$ & & & & $-\mathrm{g} \mathrm{kg}^{-1}$ & & — \\
\hline \multicolumn{10}{|c|}{ Parcela de cultivo } \\
\hline PC $0-30$ & 6.4 & $14.3 \pm 0.2$ & $1.4 \pm 0.1$ & $9.9 \pm 0.1$ & $332 \pm 5.2$ & $104 \pm 2.4$ & $151 \pm 7.8$ & $204 \pm 2.4$ & $209 \pm 2.6$ \\
\hline PC 30-60 & 6.7 & $8.0 \pm 0.4$ & $0.9 \pm 0.1$ & $8.5 \pm 0.1$ & $231 \pm 2.3$ & $142 \pm 2.1$ & $158 \pm 6.7$ & $233 \pm 1.6$ & $236 \pm 2.4$ \\
\hline \multicolumn{10}{|c|}{ Barrera de hierba } \\
\hline BE $0-2$ & 6.1 & $37.8 \pm 1.1$ & $3.3 \pm 0.1$ & $11.5 \pm 0.2$ & $184 \pm 10.3$ & $132 \pm 3.7$ & $195 \pm 7.0$ & $239 \pm 3.7$ & $250 \pm 8.7$ \\
\hline BE 2-13 & 6.3 & $18.9 \pm 0.9$ & $1.8 \pm 0.0$ & $10.5 \pm 0.3$ & $246 \pm 19.9$ & $117 \pm 5.7$ & $180 \pm 2.6$ & $224 \pm 2.1$ & $233 \pm 2.7$ \\
\hline BE 13-30 & 6.6 & $13.9 \pm 0.4$ & $1.5 \pm 0.1$ & $9.3 \pm 0.3$ & $253 \pm 15.3$ & $123 \pm 4.9$ & $172 \pm 3.5$ & $224 \pm 4.6$ & $228 \pm 5.4$ \\
\hline BE 30-60 & 6.5 & $10.9 \pm 0.7$ & $1.3 \pm 0.0$ & $8.4 \pm 0.1$ & $293 \pm 12.8$ & $104 \pm 2.8$ & $145 \pm 2.6$ & $203 \pm 5.4$ & $255 \pm 5.6$ \\
\hline \multicolumn{10}{|c|}{ Zona arbolada } \\
\hline ZB 0-2 & 5.3 & $71.1 \pm 2.6$ & $4.2 \pm 0.1$ & $16.9 \pm 0.5$ & $182 \pm 5.8$ & $92 \pm 2.1$ & $216 \pm 3.3$ & $281 \pm 6.9$ & $228 \pm 4.8$ \\
\hline ZB 2-10 & 5.0 & $52.4 \pm 0.3$ & $3.5 \pm 0.0$ & $14.8 \pm 0.0$ & $178 \pm 8.2$ & $97 \pm 2.9$ & $212 \pm 4.1$ & $297 \pm 7.6$ & $216 \pm 1.0$ \\
\hline
\end{tabular}

En general, los suelos utilizados en el estudio fueron cafés hidromorfos de textura limoarcillosa, $22 \%$ de arcillas, $46 \%$ de limos y $32 \%$ de arenas. La diferencia más importante entre ellos fue la $\mathrm{MO}$, cuyo contenido es más elevado en los suelos de la BE y la ZB. La presencia de MO disminuyó de manera clásica con la profundidad de los suelos, particularmente los de la BE.

\section{Herbicida}

El isoproturon [3-(4-isopropilfenil)-1, 1-dimetilurea], es un herbicida selectivo sistemático de la familia de las fenilureas substituidas, comúnmente utilizado en los cultivos de trigo y cebada (The Pesticide Manual, 1994). La molécula utilizada en este estudio fue el IPU uniformemente marcado al ${ }^{14} \mathrm{C}$ en el anillo bencénico. Su pureza radioactiva es superior a $95 \%$ y la actividad especifica de $2660 \mathrm{Mbq} \mathrm{mmol}^{-1}$. La molécula fue suministrada por Amersham, (Les Ulis, Francia).

\section{Estudio de la sorción}

Se prepararon cuatro soluciones de ${ }^{14} \mathrm{C}$-IPU en $\mathrm{CaCl}_{2} 10^{-2} \mathrm{M}$. Las concentraciones utilizadas 
fueron $0.24,0.56,0.99$ y $4.15 \mathrm{mg} \mathrm{L}^{-1}$. La radioactividad de estas soluciones fue de 58,82 , 107 y $177 \mathrm{~Bq} \mathrm{~mL}^{-1}$, respectivamente. Las isotermas de sorción se obtuvieron mediante la técnica batch de equilibrio. Muestras de $5 \mathrm{~g}$ de suelo se trataron por triplicado con $10 \mathrm{~mL}$ de la solución acuosa de IPU. Después de una agitación rotativa durante $24 \mathrm{~h}$ a $23 \pm 1{ }^{\circ} \mathrm{C}$, las suspensiones fueron centrifugadas a $2000 \mathrm{~g}$ durante $10 \mathrm{~min}$. Experimentos preliminares indicaron el tiempo de $24 \mathrm{~h}$ suficiente para alcanzar el equilibrio. La concentración de equilibrio $(\mathrm{Ce}$ ) del IPU se determinó a partir de la actividad de la solución sobrenadante, $1 \mathrm{~mL}$ de solución se mezcló con $4 \mathrm{~mL}$ de liquido de centello y su actividad se midió en desintegraciones por minuto en un contador de centello en medio liquido Tri-carb 2100 TR Packard Instrument. La cantidad de ${ }^{14} \mathrm{C}$-IPU retenida en el suelo $\left(x / m, \mathrm{mg}^{14} \mathrm{C}\right.$-IPU $\mathrm{kg}^{-1}$ suelo) para las diferentes concentraciones, se obtuvo por diferencia, entre las $\mathrm{Ce}$ y las concentraciones iniciales expresadas en $\mathrm{mg} \mathrm{L}^{-1}$.

\section{Estudio de la desorción}

La desorción del IPU se estudió utilizando las muestras de suelo tratadas inicialmente con la solución más concentrada durante el estudio de la sorción. Después de alcanzar el equilibrio de sorción, se removieron $10 \mathrm{~mL}$ de la solución de equilibrio y se reemplazaron por $10 \mathrm{~mL}$ de $\mathrm{CaCl}_{2}$ 10-2 $\mathrm{M}$. Las muestras fueron agitadas y centrifugadas siguiendo el protocolo descrito anteriormente. Después de cada desorción, la radioactividad presente en los sobrenadantes fue determinada por conteo de centello en medio liquido. Se realizaron en total cinco desorciones sucesivas. La cantidad de compuesto sorbida por el suelo en cada etapa de desorción fue calculada como la diferencia entre la cantidad inicial sorbida y la cantidad desorbida. Todas las determinaciones fueron llevadas a cabo por triplicado.

\section{Resultados \\ Retención del isoproturon \\ Sorción}

En la figura 4 se muestran las isotermas de sorción obtenidas para los diferentes suelos. Todas las isotermas obtenidas se ajustan a la ecuación de Freundlich: $x / m=K_{f} C e^{n}$ donde $K_{f}$ y $n$ son constantes empíricas relacionadas con la capacidad y la intensidad de la sorción, respectivamente (Calvet, 1980) con valores de $r^{2}$ entre 0.99 y 1.0. A partir de esta ecuación, se calculan los principales parámetros de la porción (Tabla 2).

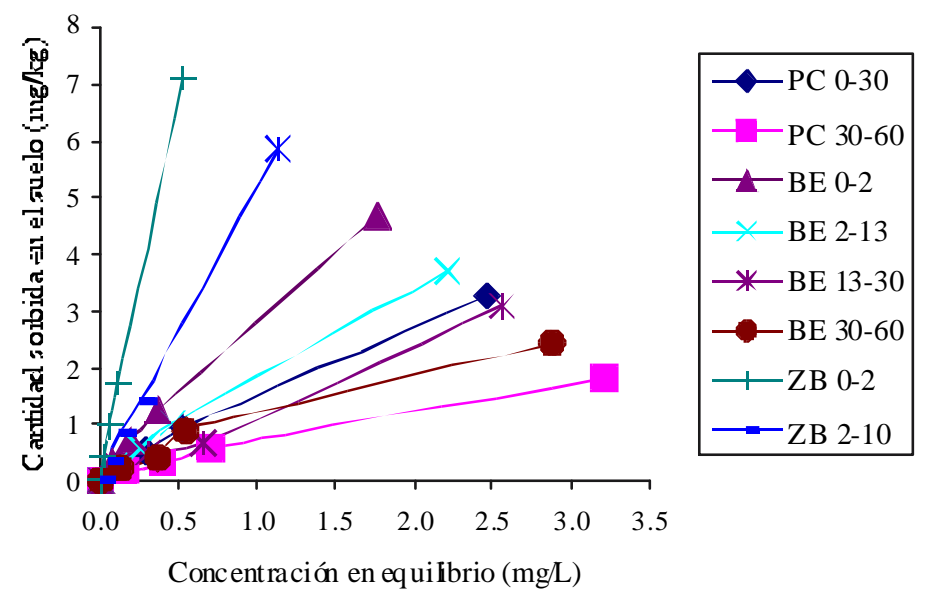

Figura 4. Isotermas de sorción del isoproturon en los diferentes horizontes de suelo de la barrera de hierbas, la zona arbolada y la parcela de cultivo 
Tabla 2. Coeficientes de sorción de Freundlich $\left(K_{f}\right.$ et $\left.n\right)$, coeficientes de correlación $\left(r^{2}\right)$, coeficientes de partición $(K d)$ y coeficientes de partición sobre la $M O(K o c)$. Los valores de Kd y Koc fueron determinados para una concentración de IPU en equilibrio de $0.15 \mathrm{mg} \mathrm{L}^{-1}$

\begin{tabular}{cccccc}
\hline $\begin{array}{c}\text { Dispositivo } \\
\text { Profundidad (cm) }\end{array}$ & $K f$ & $n$ & $r^{2}$ & $\begin{array}{c}K d \\
\left(\mathrm{~L} \mathrm{~kg}^{-1}\right)\end{array}$ & $\begin{array}{c}K o \\
\left(\mathrm{~L} \mathrm{~kg}^{-1}\right)\end{array}$ \\
\hline $\begin{array}{c}\text { Parcela de cultivo } \\
\text { PC 0-30 }\end{array}$ & $1.5 \pm 0.1$ & $0.82 \pm 0.03$ & 0.99 & $2.2 \pm 0.0$ & $144 \pm 1$ \\
PC 30-60 & $0.7 \pm 0.0$ & $0.80 \pm 0.02$ & 0.99 & $1.0 \pm 0.0$ & $129 \pm 1$ \\
Barrera de hierba & & & & \\
BE 0-2 & $2.9 \pm 0.1$ & $0.86 \pm 0.02$ & 0.99 & $3.8 \pm 0.1$ & $120 \pm 1$ \\
BE 2-13 & $1.9 \pm 0.1$ & $0.84 \pm 0.01$ & 1.00 & $2.6 \pm 0.0$ & $137 \pm 0$ \\
BE 13-30 & $1.2 \pm 0.0$ & $0.80 \pm 0.02$ & 0.96 & $1.8 \pm 0.0$ & $131 \pm 0$ \\
BE 30-60 & $1.1 \pm 0.0$ & $0.82 \pm 0.01$ & 0.96 & $1.5 \pm 0.0$ & $139 \pm 0$ \\
Zona arbolada & & & & & $14.1 \pm 0.1$ \\
ZB 0-2 & $11.9 \pm 0.2$ & $0.87 \pm 0.01$ & 0.99 & $6.2 \pm 0.0$ & $162 \pm 1$ \\
ZB 2-10 & $5.1 \pm 0.3$ & $0.89 \pm 0.03$ & 1.00 & & \\
\hline
\end{tabular}

Los valores de $n$ son inferiores a la unidad. Estos valores se sitúan entre 0.80 y 0.89 con un promedio de 0.84. De acuerdo con la clasificación propuesta por Giles et al., (1960), las isotermas obtenidas son por consiguiente del tipo de $L(n<1)$; lo que significa una reducción de los sitios de sorción disponibles cuando la concentración de la solución aumenta. Nemeth-Konda et al., (2002), también obtuvieron isotermas del tipo $L$, estudiando la retención del IPU en suelos provenientes de un bosque de castaños. El parámetro $n$ traduce la curvatura de las isotermas y da una indicación de la afinidad del compuesto por los sitios de sorción (Giles et al., 1960; Calvet, 1989). Los resultados muestran que aunque los valores de $n$ sean del mismo orden de magnitud para las diferentes ocupaciones del suelo, existe una ligera superioridad de este parámetro para los suelos de la ZB y la BE en comparación con los suelos de la PC. Esto indica una afinidad más importante del IPU por estos suelos. Las isotermas de sorción del IPU no son lineales y los valores estimados de $\mathrm{Kd}$ varían según la concentración del IPU. Los coeficientes de Kd fueron por consiguiente calculados para un mismo valor de concentración de IPU en equilibrio: $0.15 \mathrm{mg} \mathrm{L}^{-1}$ (Tabla 2). Este valor se encuentra dentro del rango de las concentraciones del IPU detectadas en las escorrentías de La Jaillière (Patty, 1997). Los valores de Kd obtenidos fueron del mismo orden de magnitud que los valores de $\mathrm{K}_{\mathrm{f}}$ calculados, por lo que el análisis de los resultados fue realizado a partir de los diferentes valores de $\mathrm{Kd}$. La comparación de los valores de $K_{d}$ muestran una capacidad de retención más importante que los suelos procedentes de la ZB y la BE (Tabla 2). La sorción del IPU es más fuerte en el horizonte superficial de la $\mathrm{ZB}$, donde el contenido de $\mathrm{MO}$ es más importante. Los valores de Kd disminuyen con la profundidad del suelo de la misma manera que el contenido de MO. Una relación similar entre el $\mathrm{Kd}$ y la $\mathrm{MO}$ ha sido ya demostrada para el IPU (Benoit et al., 1999; Coquet y Barriuso, 2002) y para otras moléculas (Kookana et al., 1992; Oliveira et al., 2001). Estos resultados son similares a los obtenidos anteriormente para el IPU en el mismo sitio experimental (Vidon, 1997). Los valores de Kd obtenidos en los horizontes superficiales, muestra que la capacidad de sorción de la ZB es de dos a cuatro veces mayor que la de la BE y la PC.

Con el fin de describir la correlación entre los diferentes valores de $K d$ y el contenido de $\mathrm{MO}$ 
de los suelos, los coeficientes $K_{d}$ fueron normalizados con respecto al contenido de carbono orgánico (Koc), según la ecuación: $K_{c}=K_{d} / C O$ donde CO (Calvet, 1980), representa el contenido de carbono orgánico (Tabla 2). Este coeficiente da cuenta de la afinidad de una molécula por la MO de un suelo. En una primera aproximación, entre más grande sea el valor de Koc, más importante es la afinidad entre el herbicida y la MO del suelo. Los valores de $\mathrm{K}_{\infty}$ obtenidos para las tres ocupaciones de suelo, muestran diferentes grados de afinidad de las moléculas por la MO. En los horizontes superficiales, el IPU tiene una afinidad superior por la MO humificada de la PC. En los suelos de la BE y la ZB, los valores de Ko c son más elevados en los horizontes más profundos que tienen los contenidos de MO más pequeños, lo que puede indicar un incremento de la influencia de las partículas minerales como las arcillas en la porción, junto con la disminución del contenido de MO (Madsen et al., 2000; Clausen y Fabricius, 2001). Estos resultados son coherentes con los de Pedersen et al., (1995) quienes observaron una sorción no despreciable del IPU en cuarzos de arenas con bajos contenidos de arcillas y carbono orgánico.

\section{Desorción}

Un fenómeno importante de histérisis entre las isotermas de sorción y de desorción fue ob- servado en todos los casos. La figura 5 presenta la cantidad de IPU no desorbida después de cinco desorciones sucesivas con $\mathrm{CaCl}_{2}$. $\mathrm{La}$ desorción del IPU es menor en las capas superficiales de la $\mathrm{BE}$ y la $\mathrm{ZB}$ que en el horizonte de trabajo 0-30 cm de la PC. La cantidad de IPU desorbida, aumenta con la profundidad en los suelos de la BE y la ZB. En los horizontes más profundos dónde la vegetación superficial tiene una menor contribución en la cantidad de MO, la retención del IPU es menor. Los resultados relativos a la cantidad no desorbida muestran que la disponibilidad (y la movilidad potencial) de este herbicida es más elevada en los horizontes de suelo más profundos.

\section{Conclusiones}

Los resultados muestran que los suelos de los dispositivos amortiguadores tienen una capacidad de retención $\left(\mathrm{K}_{\mathrm{d}}\right)$ del IPU, superior a los provenientes de la parcela de cultivo. Esta diferencia es particularmente importante en los horizontes superficiales y puede estar relacionada con la diferencia de contenido de MO. Un factor esencial del aumento de la retención en los horizontes superficiales de los suelos con hierbas y de bosque es la presencia de $\mathrm{MO}$, aún poco descompuesta, las cuales presenten elevadas capacidades de sorción de pesticidas (Lickfeldt y Branham, 1995; Benoit et al., 1999). En este sentido, estos resultados están

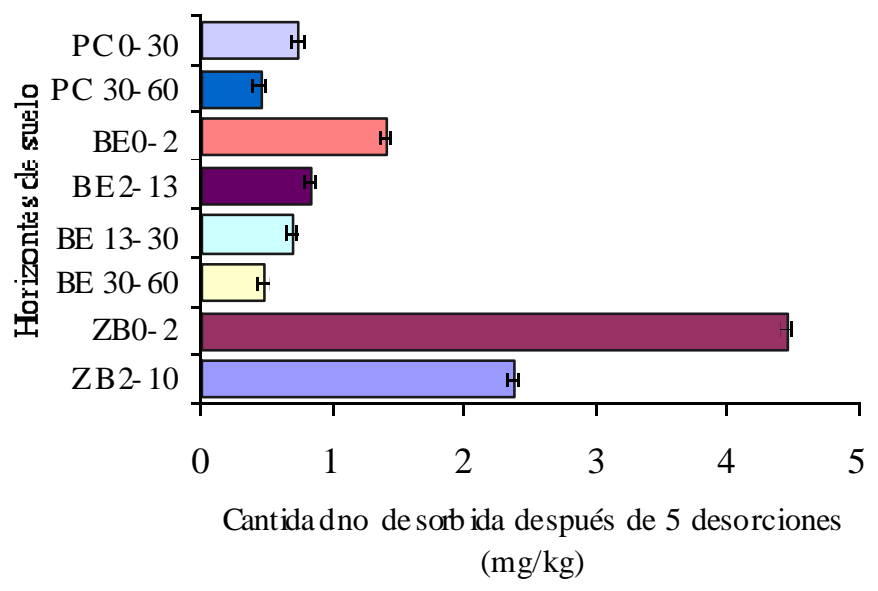

Figura 5. Cantidades de IPU no desorbida después de cinco desorciones sucesivas con $\mathrm{CaCl}_{2}$ en los diferentes horizontes de suelo de las barreras de hierba, la zona arbolada y la parcela de cultivo 
relacionados con los obtenidos en trabajos anteriores, que evocan los efectos de la vegetación en la retención de los agroquímicos presentes en las escorrentías (Patty, 1997). Para la zona arbolada, la acumulación de la capa de hojas en la superficie del suelo aumenta la capacidad de retención de manera significativa. La comparación entre los diferentes horizontes de suelos muestra una disminución importante de las capacidades de retención con la profundidad. El IPU es más difícilmente desorbable en los horizontes superficiales de los dispositivos amortiguadores que los de la parcela de cultivo. Esto indica que el IPU es más disponible y más móvil en los horizontes, más allá de $30 \mathrm{~cm}$, en donde la influencia de la vegetación en términos de aporte de $\mathrm{MO}$ es muy poca.

Estos resultados confirman el interés potencial de los dispositivos amortiguadores en la protección de los cuerpos de agua superficiales contra la contaminación de origen agrícola. Sin embargo, la eficiencia de estos dispositivos en materia de retención concierne esencialmente los horizontes superficiales donde el contenido de MO es más importante.

\section{Referencias}

AFNOR. (1999). Qualité Des Sols. Volume 2: Analyse granulométrique par sédimentation. Méthode de la pipette. Norme expérimentale (X 31-107 Juillet1983). P. 57-71.

Benoit P., Barriuso E., Vidon Ph., Réal B. (1999). Isoproturon Sorption and Degradation in a Soil from Grassed Buffer Strip. J. Environ. Qual., 28, pp. 121-129.

Bournet G., Blanplain O., Kung F. (2002). Les Pesti cides Dans les Eaux en France Actions Preventives - Bilan. Documento de la Oficina Internacional del Agua. París, Francia.

Calvet R. (1989). Adsorption of Organic Chemicals in Soils. Environ, Health Perspec., 38, pp. 145-177.

Calvet R. Tercé M., Arvieu J.C. (1980). Mise au Point Bibliographique. Adsorption des Pesticides par les Sols et Leurs Constituants II. Les facteurs de l'adsorption. Ann. Agron., 31, pp. 125-162.

Clausen L., Fabricius I. (2001). Atrazine, Isoproturon, Mecoprop, 2,4-D, and Bentazone Adsorption onto Iron Oxides. J. Environ. Qual., 30, pp. 858-869.

Coquet Y., Barriuso E. (2002). Spatial Variability of Pesti cide Adsorp tion within the Topsoil of Small Agricultural Catchments. Agronomie, 22, pp. 389-398.

CORPEN. (1997). Produits Phytosanitaires et Dispositifs Enherbés. État des Connaissances et Propositions de Mise en Ouvre. Publicación del Grupo CORPEN Arvalis "Dispositifs Enherbés". París, Francia.

Giles C.H., MacEwan T.H., Nakhwa S.N., Smith D. (1960). Studies in Adsorption. Part XI. A System of Classification of Solutions Adsorption Isotherms, and its use in Diagnosis of Adsorption Mechanisms and Measure ment of Specific Surface of Solids. J. Chem. Soc., 3, pp.3973-3993.

Kookana R.S., Aylmore L.A.G., Gerritse R.G. (1992). Time-Dependent Sorp tion of Pesti cides During Trans port in Soils. Soil Sci., 154, pp. 214-225.

Lickfeldt D.W., Branham B.E. (1995). Sorp tion of Non-Ionic Organic Compounds by Kentucky Bluegrass Leaves and Thatch. J. Environ. Qual., 24, pp.980-985.

Louchart X., Voltz M., Andrieux P., Moussa R. (1998)-Herbicide Trans port to Surface Waters at Field and Watershed Scales in a Mediterranean Vineyard Area. J. Env. Qual., 30, pp. 982-991.

Madsen L., Lindhardt B., Rosenberg P., Clausen L., Fabricius I. (2000). Pesti cides Sorption by low Organic Sediments: a Screening for Seven Herbicides. J. Environ. Qual., 29, pp. 1488-1500.

Nemeth-Konda L., Füleky G., Morovjan Gy., Cookan P. (2002). Sorption Behaviour of Acetochlor, Atrazine, Carbendazim, Diazinon, Imidacloprid and Isoproturon on Hungarian Agri cul tural Soil. Chemosphere, 48, pp. 542-552. 
Oliveira R.S., Koskinen W.C., Ferreira F.A. (2001). Sorption and Leaching Potential of Herbicides on Brazilian Soils. Weed Research, 41, pp. 97-110.

Patty L. (1997). Limi ta tion du Transfert par Ruissellement vers les Eaux Superficielles de Deux Herbicides (Isoproturon et Diflufenicanil). Méthodologie Analytique et étude de l'efficacité des Bandes Enherbées. Tesis de doctorado de la Universidad Joseph-Fourier de Grenoble, Francia.

Patty L., Real B., Gril J. (1997). The use of Grassed Buffer Strips to Remove Pesti cides, Nitrate and Soluble Phosphorus Compounds from Runoff Water. Pestic. Sci. 4, pp. 243-251.

Pedersen H.J., Kusdsk P., Helweg A. (1995). Adsorption and ED50 Values of five Soil-Applied Herbicides. Pestic. Sci., 44, pp. 131-136.

Real B., Patty L., Masson E. (1997). Bandes Enherbées: un Frein au Ruissellement des Produits Phytos. Perspectives Agricoles, 221, pp. 40-43.
Schiavon M., Perrin-Ganier C., Portal J.M. (1995). La Pollution de l'eau par les Produits Phytosanitaires: état et Origine. Agronomie, 15, pp. 157-170.

Souiller C., Coquet Y., Pot V., Benoit P., Réal B., Margoum C., Laillet B., Labat C., Vachier P., Dutertre A. (2002). Dissi pation des Produits Phytosanitaires à Ttravers un Dispositif Enherbé: Mise en Évidence des Processus mis en Jeu par Simulation de Ruissellement et Infiltrométrie (Capacités de Stockage et d'épuration des Sols de Dispositifs Enherbés vis-à-vis des Produits Phytosanitaires. Parie 1).Étude et Gestion des Sols, 9, pp. 269-285.

Vidon Ph. (1997). Rôle des Matières Organiques des Sols des Bandes Enherbées dans la Rétention et la Dégradation des Pesti cides: Cas de L'isoproturon. Tesis de maestría en «Fonctionnement Physique, Chimique et Biologique de la Biosphère Continentale». Instituto Agronómico ParísGrignon (INA P-G) y Universidad de París VI. Francia.

\section{Semblanza de los autores}

Ismael Madrigal-Monárrez. Es ingeniero bioquímico por el Instituto Tecnológico de Culiacán, maestro en ingeniería ambiental por la UNAM y doctor por el Institut National Agronomique Paris-Grignon de Francia. Actualmente es responsable del Sector de Ciencias en la Misión Permanente de México ante la Organización de las Naciones Unidas para la Educación, la Ciencia y la Cultura (UNESCO) en París.

Pierre Benoit. Es ingeniero agrónomo y doctor por el Institut National Agronomique París-Grignon de Francia. Actualmente es investigador en el Equipo Suelo de la Unité Mixte de Recherche "Environnement et Grandes Cultures" del Institut National de la Recherche Agronomique (INRA) en Francia.

Enrique Barriuso. Es ingeniero químico y doctor por la Université de Nancy de Francia. Actualmente es director adjunto de la Unité Mixte de Recherche "Environnement et Grandes Cultures" del Institut National de la Recherche Agronomique (INRA) en Francia.

Benoît Réal. Es ingeniero de estudios por el Conser va toire National des Arts et Métiers (CNAM) de Francia. Actualmente es coordinador nacional del tema "Protección de cultivos y ambiente". ARVALIS.

A. Dutertre. Es técnico de experimentación en ARVALIS Región Oeste.

M. Moquet. Es técnico de experimentación en ARVALIS Región Oeste 